\title{
An Overview of Matrix Rhythm Concept and Efficacy of Matrix Rhythm Therapy in Pathological Conditions
}

\author{
Sonali Shrivastava ${ }^{1}, \&$ K. S. Arif ${ }^{2}$ \\ ${ }^{1}$ Research Scholar, Srinivas University, Mangalore, India \\ ${ }^{1}$ Advanced Physiotherapy Center, SSIMS, Durg, India. \\ E-mail: drsonalishrivastava@gmail.com \\ ${ }^{2}$ Professor, Department of Orthopaedics, Srinivas Institute of Medical Sciences and \\ Research Center, Mangalore, India. \\ E-mail: bonehealersr@rediffmail.com
}

Type of the Paper: Review Paper.

Type of Review: Peer Reviewed.

Indexed In: OpenAIRE.

DOI: https://doi.org/10.5281/zenodo.2647796.

Google Scholar Citation: IJHSP

How to Cite this Paper:

Shrivastava, Sonali \& Arif, K. S. (2019). An Overview of Matrix Rhythm Concept and Efficacy of Matrix Rhythm Therapy in Pathological Conditions. International Journal of Health Sciences and Pharmacy (IJHSP), 3(1), 25-30.

DOI: https://doi.org/10.5281/zenodo.2647796.

International Journal of Health Sciences and Pharmacy (IJHSP)

A Refereed International Journal of Srinivas University, India.

(c) With Authors.

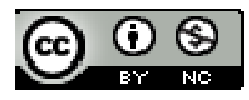

This work is licensed under a Creative Commons Attribution-Non Commercial 4.0 International License subject to proper citation to the publication source of the work.

Disclaimer: The scholarly papers as reviewed and published by the Srinivas Publications (S.P.), India are the views and opinions of their respective authors and are not the views or opinions of the SP. The SP disclaims of any harm or loss caused due to the published content to any party. 


\title{
An Overview of Matrix Rhythm Concept and Efficacy of Matrix Rhythm Therapy in Pathological Conditions
}

\author{
Sonali Shrivastava ${ }^{1}$, \& K. S. Arif ${ }^{2}$ \\ ${ }^{1}$ Research Scholar, Srinivas University, Mangalore, India \\ ${ }^{1}$ Advanced Physiotherapy Center, SSIMS, Durg, India. \\ E-mail: drsonalishrivastava@gmail.com \\ ${ }^{2}$ Professor, Department of Orthopaedics, Srinivas Institute of Medical Sciences and \\ Research Center, Mangalore, India. \\ E-mail: bonehealersr@rediffmail.com
}

\begin{abstract}
Matrix Rhythm concept was introduced in1996 based upon the concept that every intervention on a cell whether preventive, curative, regenerative or also destructive works primarily via the cells environment, that is via the extracellular matrix. Muscle cells pulsate in the frequency range of 8-12 Hertz. Muscle pulsation frequency which lie outside 8-12 Hertz range correlate positively with pains, muscle tension and other health problems. Changed muscle elasticity and plasticity are linked to variations in pulsation frequency and in logistics of the living process on the cellular level. In this paper we have reviewed the Matrix Rhythm Concept and practices of Matrix Rhythm Therapy in treating various pathological conditions. The application of matrix rhythm therapy in various conditions like frozen shoulder, post burn complications etc. are detailed.
\end{abstract}

Keywords: Cell, rhythm, matrix rhythm concept, matrix rhythm therapy.

SEARCH STRATEGY: Pubmed, Pubmed central, Google scholar, MEDLINE, COCHRANE.

\section{INTRODUCTION :}

\section{Matrix Rhythm Concept :}

During 2007, 137,000 registered German doctors were consulted by 38 to 70 patients. According to the study, the average time available for the consultation and treatment of each patient was only 6-12 minutes. The brief consultation might be a reason for the high frequency of visits to doctor. According to investigation by Allenbach Institute, 84 percent of the person's interviewed characterized the health damaging side effects of treatment methods prescribed by textbook medicine as "medium to high". In contrast, 61 percent of interviewed population considered natural healing methods as harmless. Now a days, people suffer more from mental stress. Most of the time, they do not lack only appropriate prescription for body but also the ability to search for and to understand prescriptions and to act accordingly. This extends importance of systemic medicine [1, $2]$.

\section{OBJECTIVE \& METHODOLOGY :}

The objective of this paper is to review the Matrix Rhythm Concept and practices of Matrix Rhythm Therapy in treating various pathological conditions.

Extensive search was made online and through books to study the documented research behind the Matrix Rhythm Concept and its application in various pathological conditions.

\section{STRUCTURE FORMATION IN COMPLEX DYNAMIC SYSTEM :}

Evidently, the difference between living and dead state is dissociation of elements and of the communication networks of the system. Structurally the organism remains identical prior to and immediately after the death. At the moment of death, the synchronisation, or more generally the space time cooperatively of the various participating elements in the living 
process, has suddenly been interrupted. In order to develop adequate methods for curing illness or for promoting healing process, the key task is to understand specific special character of holistic cooperation of process in a living organism $[1,10]$.

\section{Self organisation :}

Rudolf Virchow being one of the most important pioneers of modern scientific medicine wrote in his famous book "Cellular pathology" that cell together with its surrounding "territory" constitutes the smallest unit in which the living process can be identified as all living tissue is composed from cells and a cell can only come from cell. A living cell is an open system. It depends upon the constant exchange of matter, energy and information with its surroundings, that is extra cellular matrix. Henceforth as per say of Virchow, to cure diseases we need to focus on the cell and the processes of exchange of the cell with its territory "extracellular matrix. The quality of circulation in vascular systems of body including arterial, venous and lymphatic system plays a vital role in regulating the oxygen saturation of cellular system". It is always the quality of functioning of complex self -organising processes, which determines healthy (physiological) and diseased (pathological) state [1, 2, 3].

\section{APPLICATIONS OF MATRIX RHYTHM THERAPY :}

(1) Dr. Ketan Bhatikar detailed study about cases treated with matrix rhythm therapy and neuromuscular retraining in bell's palsy 32year old male who had developed facial dropping corner of mouth after bike ride in early morning was treated. He also had changes in drooling and saliva production. Bell's palsy was grade 2 in House Brackmann grading. Medical treatment was given in form of corticosteroid Valacyclovir. Physiotherapy treatment was given in form of Matrix rhythm therapy for 20 days. At the end of 3 weeks Bell's palsy was graded 1. Second case of Bell's palsy was treated with Electrical nerve stimulation for 40 days. At the end of 5th week Bell's palsy was grade 1 . This depicted matrix rhythm therapy demonstrated better and early recovery. The therapy gave a significant result on visual analog scale and muscle strength on pre-post data at every 5 day session from $1^{\text {st }}$ to $35^{\text {th }}$ session. The study concluded that matrix rhythm therapy can be continued with traditional physiotherapy protocol in the severe Bell's palsy as early recovery was seen in the patients treated with matrix rhythm therapy relative to only traditional treatment [12].

(2) Beneficial effect of Matrix Rhythm therapy was revealed by a case study on congenital muscular torticollis in 4 month old female child. She presented posture with head tilted towards left side, since birth. The child assumed a midline head posture in sitting position by $5^{\text {th }}$ session of therapeutic intervention (nine days). Therapeutic treatment included Matrix rhythm therapy and active assisted neck movements [13].

(3) A case study done by DR. Ketan Bhatikar showed positive results in treating the deep vein dysfunction. It concluded that matrix rhythm therapy along with pulsed electromagnetic field therapy and LASER therapy is more beneficial in healing of long standing non healing deep vein ulcer relative to contemporary treatment( LASER therapy, PEMF and exercise) [14].

(4) A case of 14 year old, male was treated with matrix rhythm therapy for bilateral adductor spasticity. This study showed that matrix rhythm therapy may show great effects in decreasing spasticity when with other conventional physical therapy. It also concluded that matrix rhythm therapy may increase the extensibility of a spastic muscle that can be further managed by traditional therapeutic measures [15].

(5) On 13 October, 2018 Ecronion published short communication in EC neurology. The report documented a case about 46 year old male suffering with Intra medullary ependymoma. The patient had uncontrolled random blood glucose level even after being on anti diabetic medicines. He complained of all four limbs weakness since March 2006. Matrix rhythm therapy was started as adjunct to physical therapy in January 2014. Glucose level monitoring during the entire course of therapy revealed a significant lowering of blood glucose level, moderate level sensory regain, no breathing problems, healed ulcers, decreased fatigue level [16].

(6) An experimental study was done in year 2018 on 10 patients of 40-60years at Nirmay 
physiotherapy center, Belgavi. Convenience sampling was done and Visual Analog Scale (VAS) was used to assess pain. Range of motion was measured using goniometer. Matrix rhythm therapy was applied on areas of deltoid, pectorals, trapezius, scapula. Longitudinal stroking was given relating to muscle fiber orientation. Each session of matrix rhythm therapy lasted for about 60-70 minutes. Results showed that 30 percent pain reduced. Change in VAS was found as p value of " 0.0051 " which is significant for clinical importance [17].

(7) A study was done to compare the shortterm effectiveness of Matrix Rhythm Therapy and stretching exercises in patients with frozen shoulder. Forty-three patients (mean age 52.6 years) with frozen shoulder were randomly assigned to one of 2 treatment groups: Matrix Rhythm Therapy group and stretching exercises group. Both groups were treated for 6 weeks and performed the same home exercise program. The range of motion was measured using a conventional goniometer. Constant score and the Disabilities of the Arm, Shoulder and Hand score was used for functional assessment. General health status and satisfaction of the patients were evaluated by Short Form Health Survey-36 and Global Rating of Change score, respectively. The changes in dependent variables before treatment and after 3, 6 weeks of treatment and 24 weeks of follow-up were analyzed using 2X5 mixed-model analysis of variance (ANOVA) to assess overall group, time, and group interaction effects.

Result analysis showed that both groups had significant improvement in all outcome measurements $(p<0.05)$. Two by 5 mixedmodel ANOVA revealed a significant grouptime interaction for Constant score $(\mathrm{p}=0.009)$ and Short Form Health Survey-36 physical component score $(\mathrm{p}=0.009)$ patients receiving stretching exercise at 24 weeks' follow-up. Pairwise comparison showed that SF-36 physical component score at 6 weeks and Constant score at 3 and 6 weeks follow ups were better in stretching exercise group. The patients improved with both treatment strategies; however, stretching exercise was found to be superior to Matrix Rhythm Therapy for function, physical health, and satisfaction of the patients [18].
(8) Application of matrix rhythm therapy for pain and restricted mobility in birth injuries was described in an article by Dr. Sonali [19].

(9) Effect of Matrix rhythm therapy was studied on a case of Primary lymphedema by Ayse Neriman. The cause for left lower limb oedema in 36 year old female was supposed to be genetic predisposition and developmental insufficiency. Matrix rhythm therapy was given for 20 sessions (5days /week) on left side leg, spine, and abdominal region. Global rating of change scale (GRS) was used as outcome measure. Baseline measurements of leg circumference at 1 month and 3 month decreased by $3.59 \%$ and $8.36 \%$. In GRS effect of matrix rhythm therapy on lymphedema could not be deduced. Benefit was seen in long term but no volumetric change could be seen [20].

(10) In year 2013, Ferruh and colleague did a randomised, double blind, controlled trial at Pamukkale University in Turkey, comparing the effects of Matrix rhythm therapy and conventional massage in 15 healthy young females (19-23 years). The acute effects of both treatments on circulation were studied. Matrix Rhythm therapy was applied on left lower extremity for 30 minutes (one session). Massage was give after 1 week of matrix rhythm therapy for 30 minutes (1 session). Color Doppler study was done to find blood velocity, arterial diameter, blood flow of popliteal artery and posterior tibial artery. Post matrix rhythm therapy, average increase in blood flow rate of popliteal artery was $25.29 \%$ $+/-17.23$ and posterior tibial artery was $34.33 \%+/-15.66 \%$. Post massage , average increase in blood flow of popliteal artery was $17.84 \%+/-17.23 \%$ and posterior tibial artery was $16.07 \%+/-10.28 \%$. The study concluded that there was relatively better improvement in blood circulation after matrix rhythm therapy [21].

(11) In October 2010 and August 2011, at Istanbul, burn patients (20-60 years) with second degree and third degree burn in upper extremity, were treated with matrix rhythm therapy. Physiotherapy treatment included matrix rhythm therapy, whirlpool therapy, and exercise therapy. Matrix rhythm therapy was given for 15-45 minutes, depending upon size of region, 5 days a week. Exercise therapy included Active range of motion and passive 
range of exercise, stretching, strengthening and proprioceptive- neuro-muscular facilitation exercise. Outcome measures used were Skin flexibility, Schmidt control instrument durometer, sensory functionmonofilament test, touch test, sensory evaluation. No change was found in muscle strength and muscle flexibility. Active range of motion increased by 13.4 degrees and passive range of motion increased by 12.56 degree. Sensory function improved by 0.38 . Muscle strength increased by 69 Newton [8].

(12) A study evaluating theories relating to matrix rhythm therapy curing pain and illness with alpha vibrations was published. The study described vibrations and their indications in sport injuries, the principle of the matrix rhythm therapy and yoga [9].

(13) The most extensive study was carried out by Anne B.M. Jager with support from the State Insurance Institution (Landesversicherungsanstalt) of the German State of Baden-Wurttenberg in context of a doctoral thesis at Hannover University from April through August 2004 on 80 patients with back problems. Patients were mostly skilled and semi skilled workers engaged in monotonous assembly line work on a piece work basis. All of them had a long pre history of protracted, unsuccessful therapy for a variety of conditions including lumboischialgia (back pain radiating as far as legs) and cervicobrachialgia . In hospitalised patients there was a control group. Patients from both group each received 4 individual treatments of 30 minutes with the Matrixmobil. To avoid placebo effect person giving treatment, time of treatment, environment of treatment was frequently changed. The results were analysed using standardised questions relating to subjective experience of treatment with respect to its effect on pain intensity. Changes in shape of the back were measured using Medimouse device of Swiss firm Idiag. Clinical laboratory measurements like blood $\mathrm{CO}_{2}, \mathrm{Ph}$ and oxygen partial pressure were documented. Long term effect of treatment was carried out in followup after 3months. The measurements showed in movement amplitudes in saggital and frontal planes. Positive results were obtained for more than $83 \%$ of treated population (72 treated). 12 out of 72 treated persons interviewed said they had not felt any lasting improvement, after closer indirect questions, 3 spoke of a gradual improvement in 3 month course. The researcher concluded that strong correlation exists between investor's theories and the results in practice.[1, p169]

(14) A cost benefit analysis carried out by C Probster from BKK Faber-Castell and Partner one year after the application of Matrix Rhythm Therapy estimated financial savings of $40 \%$ compared to all previously used treatment methods at the onsite medical services of Daimler-Chrysler Company in Sindelfingen [1, p171].

\section{RESULT :}

Thirteen out of fourteen studies described positive effects of application of Matrix Rhythm Therapy. Only one study described stretching exercise as superior to Matrix Rhythm Therapy for function, physical health, and satisfaction of the patients [18]. Benefits stated are in terms of pain level, mobility, flexibility, range of motion, cost effectiveness, impairment, duration of recovery, posture.

\section{CONCLUSION :}

Matrix Rhythm concept is highly efficacious in treating patients with various pathologies and stress associated problems. Application of Matrixmobil has excellent therapeutic efficiency in treating pain and movement dysfunction.

\section{Future suggestion}

More clinical evidences are needed to explore the efficacy of Matrix Rhythm Therapy in conditions like SIJ dysfunction, Knee pain, vertigo, trigeminal neuralgia, headache, plantar fascitis, autistic spectrum disorder, hand function, sinusitis, supraspinous tendonitis, ligament injuries, speech and hearing impairements, stroke, unhealed ulcers.

\section{REFERENCES :}

[1] The Matrix Concept Medicine of the $21^{\text {st }}$ century: Fundamentals of Matrix Rhythm Therapy -BOOK by Ulrich G. Randoll.

[2] The principles of Matrix Rhythm TherapyDr. Ulrich G. Randoll.

[3] Matrix Rhythm Therapy and the lymphatic system- Dr. Ulrich Randoll.

[4] Matrix Rhythmus Therapie [home page on 
the Internet]. Online document at: www.marhythe.in/index.php/aboutmarhyt her/ the-therapy Accessed April 14, 2010.

[5] Randoll UG, Hennig FF. A new approach for the treatment of low back pain, matrix-rhythm-therapy. Osteologie. 2001; Suppl:66.

[6] Randoll UG, Hennig FF. Preoperative and postoperative matrix-rhythm-therapy to optimize hip surgery. Osteologie. 2001;Suppl:149.

[7] Jäger A, Chan D "The effect of Matrix Rhythm Therapy on backpain patients" 2nd National Physiotherapy and RehabilitationCongress. 2009 May 14-15; Izmir. P.132.

[8] Zu" beyir Sari et al "The application of matrix rhythm therapy as a new clinical modality in burn physiotherapyprogrammes”. Burns 5(40), 909- 9011. $\quad$ http://dx.doi.org/10.101 6/j.burns.2013.11.009.

[9] Randoll UG. Matrix-Rhythm-Therapy: Utilizing the entrainment effect to optimize body performance and tissue regeneration in chronic diseases. Yoga seminar, Geneve November 2014.

[10] Ulrich G Randoll, Friedrich F Henning. Cell biological basics, theory and practice; pt_zeitschrift fur physiotherapeuten 2009, 6(61).

[11] Effects of MaRhyThe ${ }^{\circledR}$ | Matrix Rhythmus Therapie, India [Internet]. Marhythe.in. 2017 [cited 10th December 2017]. Available from: http://marhythe.in/aboutmarhythe/effects-of-marhythe.

[12] Ketan Bhatikar: Effect of matrix rhythm therapy and facial neuromuscular retraining program in bell's palsy report, EJPMR, 2018,5(11), 280-283.

[13] Sonali Shrivastava, \& K.S. Arif: MRT as a major component of physical therapy intervention for a child with congenital muscular torticollis: A case report; International journal of health sciences and pharmacy ; December 2018 (2)-issue 2.
[14] Bhatikar: Effect of matrix rhythm therapy on chronic vein dysfunction, deep foot ulcer: a case report, JYP, 2018, 6(5).

[15] Bhatikar: Effect of Matrix rhythm therapy in $\mathrm{B} / \mathrm{L}$ adductor muscle tightness in pediatric cerebral palsy: a case report. J Palliat Care Med 2019, 9(1).

[16] Sonali Shrivastava, K.S. Arif: Matrix Rhythm Therapy for intramedullary ependymoma incidence in type2 Diabetes mellitus; 2019, EC Neurolgy 11.190-93.

[17] Varun Naik, SandeepBhagwat, Tanvi Pathania and Farhana Bootwala :Effectiveness of matrix rhythm therapy in frozen shoulder with respect to ROM and pain- An experimental study: IJAR 2018; 4(1): 73-76 www.allresearchjournal.com.

[18] Çelik D, Türkel N, Atalar AC. Comparison of Matrix Rhythm Therapy and Stretching Exercises on Frozen Shoulder: Randomised Controlled Trial. 2016; 27(3)81-88.

[19] Sonali Shrivastava: Matrix rhythm therapy : A new dimension in pain management and restricted mobility-Birth injuries; December2015, International journal of Advance Research in science and engineering, special issue no. 11(4), 3-118.

[20] Ayse Neriman Narin, Ayse Zengin Alpozgen, Hilal Denizoglu Kulli: Effects of matrix rhythm therapy on primary lymphedema: a case report ; J. Phys. Ther. Sci. 2016, 28: 2418-2421.

[21] Ferruh Taspinar, Ummuhan Bas Aslan, Nuran Sabir, and Ugur Cavlak: Implementation of Matrix Rhythm Therapy and Conventional Massage in Young Females and comparison of their acute effects in circulation. Journal of alternative and complementary medicine Volume 19, Number 10, 2013, pp. 826832, Inc. DOI: 10.1089/acm.2012.0932. 